\title{
Future Changes in Mean and Extreme Monsoon Precipitation in the Middle and Lower Yangtze River Basin, China, in the CMIP5 Models $\mathscr{A}$
}

\author{
Yanjuan Wu, ${ }^{\mathrm{a}, \mathrm{b}}$ ShuAng-Ye Wu, ${ }^{\mathrm{c}, \mathrm{d}}$ Jiahong Wen, ${ }^{\mathrm{a}}$ Felipe Tagle, ${ }^{\mathrm{e}}$ Ming Xu, ${ }^{\mathrm{f}}$ And Jianguo Tan ${ }^{\mathrm{g}}$ \\ ${ }^{a}$ Department of Geography, Shanghai Normal University, Shanghai, China \\ ${ }^{\mathrm{b}}$ Key Laboratory of Watershed Geographic Sciences, Nanjing Institute of Geography and Limnology, Chinese \\ Academy of Sciences, Nanjing, China \\ ${ }^{\mathrm{c}}$ Geology Department, University of Dayton, Dayton, Ohio \\ ${ }^{\mathrm{d}}$ School of Geographic and Oceanic Sciences, Nanjing University, Nanjing, China \\ ${ }^{\text {e }}$ School of Operations Research and Information Engineering, Cornell University, Ithaca, New York \\ ${ }^{\mathrm{f}}$ Shanghai Typhoon Institute, China Meteorological Administration, Shanghai, China \\ ${ }^{\mathrm{g}}$ Shanghai Institute of Meteorological Science, Shanghai, China
}

(Manuscript received 25 January 2016, in final form 14 July 2016)

\begin{abstract}
In this study, the potential future changes of mean and extreme precipitation in the middle and lower Yangtze River basin (MLYRB), eastern China, are assessed using the models of phase 5 of the Coupled Model Intercomparison Project (CMIP5). Historical model simulations are first compared with observations in order to evaluate model performance. In general, the models simulate the precipitation mean and frequency better than the precipitation intensity and extremes, but still have difficulty capturing precipitation patterns over complex terrains. They tend to overestimate precipitation mean, frequency, and intensity while underestimating the extremes. After correcting for model biases, the spatial variation of mean precipitation projected by the multimodel ensemble mean (MME) is improved, so the MME after the bias correction is used to project changes for the years 2021-50 and 2071-2100 relative to 1971-2000 under two emission scenarios: RCP4.5 and RCP8.5. Results show that with global warming, precipitation will become less frequent but more intense over the MLYRB. Relative changes in extremes generally exceed those in mean precipitation. Moreover, increased precipitation extremes are also expected even in places where mean precipitation is projected to decrease in 2021-50. The overall increase in extreme precipitation could potentially lead to more frequent floods in this already flood-prone region.
\end{abstract}

\section{Introduction}

The middle and lower Yangtze River basin (MLYRB) is located in eastern China. It is one of the most important agricultural and industrial regions in China, contributing to large portions of the nation's total gross domestic product and grain production (Fig. 1). Flooding along the river has always been a major problem in this region, particularly during the monsoon season from

Supplemental information related to this paper is available at the Journals Online website: http://dx.doi.org/10.1175/ JHM-D-16-0033.s1.

Corresponding author address: Shuang-Ye Wu, Geology Department, University of Dayton, 300 College Park, Dayton, OH 45469-2364.

E-mail: swu001@udayton.edu; jhwen@shnu.edu.cn
May to September (Jiang et al. 2008). Meanwhile, the relatively dense population and large cities along the river make the floods more deadly and costly (Jiang and Shi 2003). The 1998 Yangtze River floods resulted in 3704 dead, 15 million homeless, and \$26 billion (U.S. dollars) in economic loss (Wang 2001). A significant increase in precipitation has been observed in the MLYRB in the late twentieth century. Many studies indicate that the observed increase is mostly associated with an increase of high-intensity precipitation events resulting in more frequent floods (Zhai et al. 2005). Su et al. (2006) have observed more frequent long-duration extreme events over the MLYRB, increasing the risk of larger floods. Wu et al. (2004) suggest that humaninduced global warming may be partly responsible for more frequent and intense floods over the Yangtze River basin during the past several decades. Many studies indicate that global warming is likely to further 


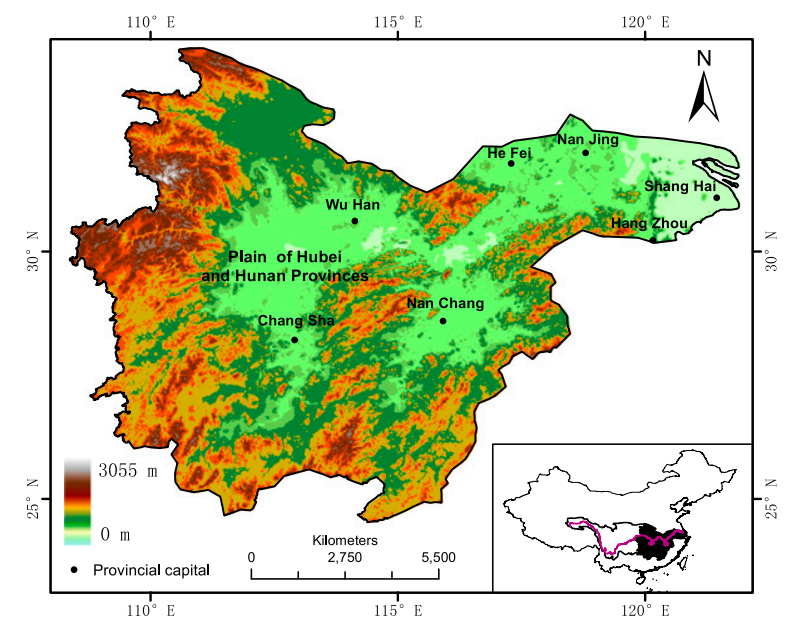

FIG. 1. Map of the MLYRB.

change the precipitation patterns in the future (Hegerl et al. 2010).Therefore, it is extremely important to examine such potential changes in both mean and extreme precipitation patterns in this important region to provide useful information for decisionmaking in climate change mitigation and adaptation. This study focuses on the MLYRB, encompassing an area from $24^{\circ}$ to $34^{\circ} \mathrm{N}$ and from $108^{\circ}$ to $122^{\circ} \mathrm{E}$ (Fig. 1).

Several recent studies have evaluated the models in phase 5 of the Coupled Model Intercomparison Project (CMIP5) for their ability to simulate precipitation and used them to examine the potential precipitation changes at global and regional scales (Kharin et al. 2013; Sillmann et al. 2013a,b; Wuebbles et al. 2014). Kharin et al. (2013) analyzed extreme precipitation events with a 20-yr return interval in CMIP5 models and found that the multimodel ensemble could simulate them well over the extratropics, but large uncertainties exist in the tropics and subtropical regions. CMIP5 models are also applied to explore future precipitation changes in China. Several studies suggest that the models underestimate the summer precipitation over eastern China (Chen and Sun 2013; Chen and Frauenfeld 2014; Huang et al. 2013). Most studies project an increase in precipitation for the region by the end of the twenty-first century, with a greater increase in the north than in the south (Tian et al. 2015; Xu and Xu 2012). However, most existing studies focus on the mean precipitation (Chen and Frauenfeld 2014; Tian et al. 2015; Xu and Xu 2012). To detect the effects of warmer climate on the current and future characteristics of precipitation, it is extremely important to examine the changes in both the mean state and extreme events. Some studies examined the changes in extreme precipitation, but were limited to the use of a set of simple indices, such as those developed by the Expert Team on Climate Change Detection and Indices
(ETCCDI; Chen and Sun 2015; Xu et al. 2015). In this study, we examine the changes in extremes in more depth by incorporating statistical methods derived from the extreme value theory.

This study focuses on the MLYRB, a region with the most severe floods and high socioeconomic costs. It aims to project how future climate change will affect mean and extreme precipitation during the monsoon season, defined as from May to September for the study area. Compared with previous studies, we have made the following methodological adjustments. First, most previous studies examined the potential changes in precipitation for all of China or for large subregions, combining CMIP5 models of various spatial resolutions. Therefore, results were usually presented in a coarse resolution that did not provide sufficient spatial details for this particular region. In this study, we selected six high-resolution CMIP5 models (with cell size ranging from $1^{\circ}$ to $1.8^{\circ}$ ) and only used those as our basis for assessment. Second, instead of using raw model output data, we evaluated model biases by comparing results of historical runs with observed values and applied statistical methods to correct model biases before they were used to assess future changes. Third, we used peak over threshold (POT), a relatively new approach in statistical analysis of extreme events, to establish present and future probabilities and magnitudes of extreme precipitation events, based on which a detailed comparison could be made. Finally, many studies indicate a close connection between the East Asian summer monsoon (EASM) strength and the rainy season precipitation in the MLYRB (Li and Zeng 2002). However, whether this relationship will remain unchanged under global warming has rarely been investigated. In this study, we examine how precipitation change is linked to changes in the EASM strength in the future. Major objectives of this study include the following:

1) Evaluate a set of high-resolution CMIP5 models on their ability to simulate mean and extreme monsoon precipitation for the study area.

2) Project future changes in mean and extreme precipitation during the monsoon season for the years 2021-50 and 2071-2100 relative to 1971-2000 under two emission scenarios: RCP4.5 and RCP8.5.

3) Examine the link between future changes in precipitation pattern and EASM.

The remainder of this paper contains three sections. Section 2 provides a brief description on the datasets and methodology used in this study. Section 3 presents results of potential changes in mean and extreme precipitation for two future time periods under two different emission scenarios. Section 4 provides a discussion of the results and major conclusions of the study. 
TABLE 1. List of 6 CMIP5 models used in our study.

\begin{tabular}{|c|c|c|}
\hline Model name & Modeling center & Resolution \\
\hline $\begin{array}{l}\text { Commonwealth Scientific and Industrial Research Organisa- } \\
\text { tion Mark 3.6.0 (CSIRO Mk3.6.0) }\end{array}$ & CSIRO, Australia & $1.8497^{\circ} \times 1.875^{\circ}$ \\
\hline $\begin{array}{l}\text { Hadley Centre Global Environment Model, version 2-Earth } \\
\text { System (HadGEM2-ES) }\end{array}$ & $\begin{array}{l}\text { Met Office Hadley Centre, United } \\
\text { Kingdom }\end{array}$ & $1.25^{\circ} \times 1.875^{\circ}$ \\
\hline $\begin{array}{l}\text { Model for Interdisciplinary Research on Climate, version } 5 \\
\text { (MIROC5) }\end{array}$ & $\begin{array}{l}\text { Atmosphere and Ocean Research In- } \\
\text { stitute (University of Tokyo), National } \\
\text { Institute for Environmental Studies, } \\
\text { and JAMSTEC, Japan }\end{array}$ & $1.4^{\circ} \times 1.4^{\circ}$ \\
\hline $\begin{array}{l}\text { Max Planck Institute Earth System Model, low resolution } \\
\text { (MPI-ESM-LR) }\end{array}$ & $\begin{array}{l}\text { Max Planck Institute for Meteorology, } \\
\text { Germany }\end{array}$ & $1.865^{\circ} \times 1.875^{\circ}$ \\
\hline $\begin{array}{l}\text { Meteorological Research Institute Coupled Atmosphere- } \\
\text { Ocean General Circulation Model, version } 3 \text { (MRI-CGCM3) }\end{array}$ & Meteorological Research Institute, Japan & $1.2145^{\circ} \times 1.125^{\circ}$ \\
\hline Community Climate System Model, version 4 (CCSM4) & NCAR, United States & $0.9424^{\circ} \times 1.25^{\circ}$ \\
\hline
\end{tabular}

\section{Data and methodology}

\section{a. Data}

The outputs of six high-resolution global climate models in CMIP5 are selected in this study to project future changes of precipitation in the MLYRB (Table 1). These models include both retrospective twentieth century climate simulations and twenty-first century climate projections under the RCP4.5 and RCP8.5 scenarios. The historical climate simulations cover 30 years from 1971 to 2000, and the future projections are developed for both the near future (2021-50) and the long-term future (2071-2100). Most models have a resolution between $1^{\circ}$ and $1.8^{\circ}$ of latitude/longitude.

The gridded daily precipitation for China (referred to as CN0.5) is used to evaluate the models (Zhao 2012). The data are distributed by the China Meteorological Data Sharing Service System (http://data. $\mathrm{cma} . \mathrm{cn} /$ ). The data have the spatial resolution of $0.5^{\circ}$. The CN0.5 is interpolated from observations at 2472 weather stations using thin-plate spline smoothing, incorporating varying degrees of topographic dependence, with the degree of data smoothing determined by minimizing the generalized cross validation (Hutchinson 1998a,b). All weather station data were subject to strict quality-control procedures by the China Meteorological Administration before the interpolation. Comparison between the $\mathrm{CN} 0.5$ and the raw station data shows high consistency and small bias between the two. However, error increases in regions where rain stations are sparse. The relatively dense station network in eastern China ensures high data quality in our study area (MLYRB).

A subset of the data is extracted for the study area for 1971-2000, the same period as model historical runs. To facilitate comparison, all climate model data are resampled to the $0.5^{\circ} \times 0.5^{\circ}$ grid as the observed data (CN05) using thin-plate smoothing spline. In addition, the monthly mean wind speed at $850 \mathrm{hPa}$ data is obtained from the National Centers for Environmental Prediction-National Center for Atmospheric Research (NCEP-NCAR) reanalyses dataset (http://www.esrl. noaa.gov/psd/data/gridded/data.ncep.reanalysis.html) for the period 1971-2000. It is used to calculate EASM index and to examine the relationship between precipitation and EASM strength.

\section{b. Variables}

\section{1) Precipitation Indices}

To assess potential changes in the characteristics of precipitation with warming climate, it is important to examine both the mean state and extreme events. For the mean state, we define the following precipitation indices for the monsoon season, defined as from May to September:

- Wet days (frequency): number of days with precipitation $\geq 1 \mathrm{~mm}$ day $^{-1}$;

- Mean (mean): mean daily precipitation (mm);

- Intensity (intensity): mean precipitation of wet days, an indication of precipitation intensity $\left(\mathrm{mm} \mathrm{day}^{-1}\right)$.

In addition, we define extreme precipitation events in terms of their return intervals. In this study, we examine the present and future magnitudes of 5- and 20-yr events, derived from using the generalized Pareto distribution (GPD) based on POT series. More details of this method are presented in section 2.

\section{2) EASM INDEX}

Many indices exist to measure the EASM intensity. In this study, we use the EASM index developed by Li and Zeng (2002), which is defined directly from monthly wind speeds. This index has been widely used in previous climate change studies ( $\mathrm{Li}$ and Zeng 2002; Wang et al. 2008). It is defined as follows: 


$$
\delta=\frac{\left\|\overline{\mathbf{v}}_{1}-\overline{\mathbf{v}}_{i}\right\|}{\|\overline{\mathbf{v}}\|}-2,
$$

where $\overline{\mathbf{v}}_{1}, \overline{\mathbf{v}}_{i}$ are the January climatological and monthly wind vectors at a point, respectively, and $\overline{\mathbf{v}}$ is the mean of January and July climatological wind vectors at the same point. The norm $\|A\|$ is defined as

$$
\|A\|=\left(\iint_{S}|A|^{2} d S\right)^{1 / 2}
$$

where $S$ denotes the domain of integration $\left(10^{\circ}-40^{\circ} \mathrm{N}\right.$, $\left.110^{\circ}-140^{\circ} \mathrm{E}\right)$. For example, we calculate at a point $(i, j)$,

$$
\begin{aligned}
\left\|A_{i, j}\right\| \approx & \sqrt{a}\left[\left(\left|A_{i-1, j}^{2}\right|+\left|A_{i, j}^{2}\right|+\left|A_{i+1, j}^{2}\right|\right) \cos \varphi_{j}\right. \\
& \left.+\left|A_{i, j-1}^{2}\right| \cos \varphi_{j-1}+\left|A_{i, j+1}^{2}\right| \cos \varphi_{j+1}\right]^{1 / 2},
\end{aligned}
$$

where $a$ is the mean radius of the earth and $\varphi_{j}$ is the latitude at the point $(i, j)$. This index is constructed as the dynamical normalized seasonality of the wind field. It uses the magnitude of seasonal difference of the wind field as an indication of monsoon strength.

\section{c. Methodology}

\section{1) Model evaluation}

The Taylor diagram is a useful visual tool to summarize the degree of similarity between simulated and observed values of a climate field (Taylor 2001). This diagram displays the centered root-mean-square difference $E$, the correlation coefficient $r$, and the ratio of standard deviations $\sigma$ of a pair of simulated and observed values as a single point on a two-dimensional plot, so that different models can be compared and evaluated (Pincus et al. 2008). In this study, we use the Taylor diagram to evaluate the models' ability to simulate mean and extreme precipitation during the monsoon season over MLYRB. Summary statistics for each model as well as model ensemble mean were computed with respect to the observed values.

\section{2) CORRECT BIAS}

Despite their improved performance, the CMIP5 models still contain significant biases (Knutti and Sedláček 2013). Biases in GCM simulations not only affect the mean precipitation amount, but the shape of the distribution. For example, many models tend to overestimate light precipitation frequency but underestimate extreme precipitation magnitudes (Stephens et al. 2010). Therefore, bias correction is often necessary for developing more accurate future climate projections. In this study, the quantile mapping technique was used to correct biases in the model output. Quantile mapping is a type of statistical transformation that equates cumulative distribution functions (CDFs) of observed data $x_{o, h}\left(F_{o, h}\right)$ and modeled data $x_{m, h}\left(F_{m, h}\right)$ in a historical period. This leads to the following transfer function for a modeled value $x_{m, p}$ in a projected future period:

$$
\hat{x}_{m, p}=F_{o, h}^{-1}\left[F_{m, h}\left(x_{m, p}\right)\right],
$$

where $\hat{x}_{m, p}$ is the bias-corrected modeled data for a projected future period; $F_{o, h}^{-1}$ is the inverse $\mathrm{CDF}$ (i.e., quantile function) of observed data $x_{o, h} ; F_{m, h}$ is the CDF of the modeled historical data $x_{m, h}$; and $x_{m, p}$ is the uncorrected modeled future projection data. More details can be found in Gudmundsson et al. (2012) and Wu (2012).

\section{3) Peaks over threshold}

The probability and magnitude of extreme events are often studied through a branch of statistics known as extreme value analysis (Coles 2001). The common approach usually involves fitting an appropriate theoretical distribution function (such as the extreme value distribution) on block maxima (minima) series. In most situations it is customary and convenient to use the annual maxima (minima). This is sometimes considered a wasteful approach to extreme value modeling if an entire time series of daily data is available (Coles 2001). In this study, an alternative approach is used, which relies on extracting from a continuous record the peak values that exceed a certain threshold for the entire series (Pickands 1975). This method is generally referred to as the POT method. In this study, the threshold is set at the 95th percentile of daily precipitation values during monsoon season (Cooley and Sain 2010; Tomassini and Jacob 2009). For POT data, the GPD is often used to model the frequency and magnitudes of exceedances, which is also adopted in this study. Based on Coles (2001), daily precipitations $X$ in exceedance above a certain threshold $u$ are well represented by a GPD with scale and shape parameters denoted by $\sigma$ and $\xi$, respectively (Pickands 1975). Then, given $x>u$, the probability of $X$ exceeding $x$ is given as

$$
P(X>x \mid X>u)=\left[1+\xi\left(\frac{x-u}{\sigma}\right)\right]^{-1 / \xi} .
$$

If $\zeta_{u}$ denotes the probability of exceeding the threshold $u$, the magnitude of a precipitation event with $N(\mathrm{yr})$ return level $z_{N}$ is given by

$$
z_{N}=u+\frac{\sigma}{\xi}\left[\left(N n_{y} \zeta_{u}\right)^{\xi}-1\right],
$$

where $n_{y}$ is the number of data per year. 


\section{4) Declustering}

The major assumption in POT analysis is that the values of exceedances are independent (Coles 2001). However, daily precipitation exhibits temporal dependence, which also occurs at high values. In this study, we assume that two exceedance events are independent if there is at least one day without rainfall between them. Consecutive days exceeding the threshold are treated as a single event with only the day with maximum value of the cluster kept in the series. The GPD is then fit to the declustered POT series at each grid.

\section{Results and discussion}

\section{a. Model performance in simulating precipitation characteristics for 1971-2000}

\section{1) Metric AnAlysis of MOdel PERformance}

We first calculate the mean values for all precipitation indices for both modeled historical data and the observed data for 1971-2000 during the monsoon season from May to September at each grid point within the study area. Based on these values, we then calculated the summary statistics of the centered root-mean-square difference, the correlation coefficient, and the ratio of standard deviations between each pair of simulated and observed values for all models and the multimodel ensemble mean (MME). The results are plotted on the Taylor diagram (Fig. 2). Performance varies among the different models for simulating different variables. In general, model performance is higher for mean precipitation indices (amount and frequency) and lower for extreme precipitation indices $\left(P_{5}\right.$ and $\left.P_{20}\right)$. With extreme precipitation, models performed better for less extreme events $\left(P_{5}\right)$ than more extreme events $\left(P_{20}\right)$. In addition, modeled precipitation values have greater variance than observed for the mean precipitation and frequency, as indicated by the $\sigma$ larger than 1 . On the other hand, $\sigma$ is smaller than 1 for extreme precipitation and precipitation intensity, suggesting less variance in modeled values than observed values for these variables.

The impact of model resolution on its ability to simulate precipitation has been widely discussed in previous studies with inconclusive results. Some suggest higherresolution models produce better results, particularly regarding extreme precipitation (Huang et al. 2013; Wehner et al. 2010). Others find no evident impact of the model horizontal resolution on its performance in simulating precipitation (Chen and Frauenfeld 2014; Song and Zhou 2014). Our analysis uses six relatively highresolution GCMs. Among them, the model with the highest resolution, CCSM4, has the best performance for simulating the mean state precipitation, that is, mean, frequency, and intensity. However, for the extreme events $\left(P_{5}\right.$ and $\left.P_{20}\right)$, CCSM4 performs poorly, whereas the lowest-resolution model (CSIRO Mk3.6.0) outperforms all others. These results show that higher resolution does not necessarily lead to the improvement in simulating precipitation, suggesting that resolution may not be the only limiting factor in the simulation, and that other factors such as model parameterization and model physics schemes are also important in the simulation monsoon system (Chen et al. 2010). In this study, the MME generally outperforms any individual models for most indices. Sillmann et al. (2013a) suggest that averaging across a range of models reduces some systematic errors in individual models. On the other hand, Knutti et al. (2010) indicate that such averaging could lead to the loss of information.

\section{2) Precipitation SPAtial PATterns}

As it has the best overall performance, we use MME to evaluate models' ability to simulate the spatial pattern for monsoon precipitation in the study area (MLYRB). Figure 3 shows the spatial patterns of all precipitation indices for the observed values, MME values, and the difference between them (bias). In summer, MLYRB is under the influence of the EASM, which transports moisture from the South China Sea to inland regions. Therefore, precipitation should be high in the south and gradually decrease northward as it gets farther away from the moisture source (Shi et al. 2012). As we can see, MME can capture this characteristic. In reality, the complex terrain (Fig. 1) disrupts this general pattern, causing high precipitation over the mountainous regions in the eastern and western MLYRB because of orographic lifting and less precipitation in the rainshadow region in central MLYRB. In general, the CMIP5 models and MME fail to simulate the complex precipitation pattern in mountainous regions because of the coarse resolutions of the climate models, which makes it difficult to resolve complex topography. A more detailed discussion on how spatial resolution impacts model performance is provided in the supplemental material (section S1).

In general, compared with observations, the CMIP5 MME tends to overestimate the mean monsoon precipitation over MLYRB, with an area-weighted bias of $10.2 \%$. This is largely due to the overestimation of the precipitation frequency $(9.2 \%)$, with slight overestimation of intensity $(2.1 \%)$. Spatially, the overestimation of precipitation occurs mainly in the rain-shadow area of highelevation regions, such as in the plains of Hubei Province and Hunan Province and the south of MLYRB. Chen and Sun (2013) indicate that the overestimation is mainly due 


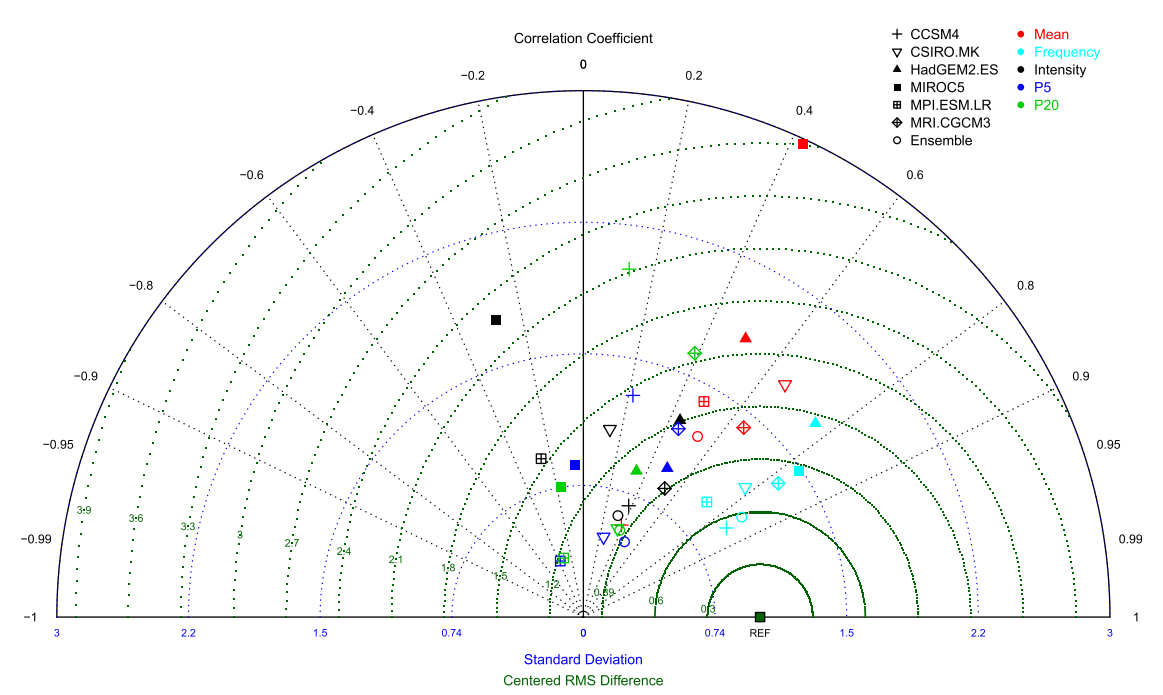

FIG. 2. Multivariable Taylor diagram of simulations of all indices from CMIP5 during 1971-2000 over the MLYRB.

to the large positive bias of the frequency of light precipitation (precipitation $<10 \mathrm{~mm} \mathrm{day}^{-1}$ ). Stephens et al. (2010) suggest precipitation is simulated too often and too lightly in climate models. Our results show that, despite the overestimation of mean precipitation, the MME underestimates extreme precipitation events, with an areaweighted bias at $-9.3 \%$ for $P_{5}$ and $-6.6 \%$ for $P_{20}$. Even though the overall bias is mostly less than $10 \%$, it is highly variable spatially for both mean and extreme precipitation (Table 2).

Based on the above analysis, we can see the MME does not capture well the spatial patterns of observed precipitation, particularly for the extreme events. The bias between the MME and observation is highly spatially variable. So in order to establish more reliable projections required for local climate impact assessment, it is necessary to correct the bias of the raw model output.

\section{b. Projected future precipitation changes for the monsoon season}

Figure 4 shows the spatial changes in the MME projections after the bias correction of mean and extreme precipitation during the monsoon season, as percentage change of simulated values in 2021-50 and 2071-2100 relative to the 1971-2000 reference period under the RCP4.5 and RCP8.5 emission scenarios. A detailed examination on the impact of bias correction on model results is provided in the supplemental material (section S2). In the near future, mean precipitation is likely to increase slightly for the whole study area under both RCPs $(2.0 \%$ for RCP 4.5 and $0.6 \%$ for RCP8.5), but with great spatial variability. Although the mean precipitation is increasing under both emission scenarios, a decrease is also found at some parts of this region. Precipitation frequency is projected to decrease slightly $(-0.3 \%)$ for the study area as a whole under RCP4.5, but decrease more significantly over the entire study area under RCP8.5 at $-2.7 \%$. Precipitation intensity is projected to increase by $6.2 \%$ under RCP 4.5 and $7.4 \%$ under RCP8.5. The projected increases in extreme precipitation are substantially larger. The $P_{5}$ magnitude is expected to increase by $25.5 \%$ in RCP 4.5 and $29.2 \%$ in RCP 8.5 , whereas $P_{20}$ will increase by $27.9 \%$ in RCP4.5 and $32.7 \%$ in RCP8.5. In addition, the increase in $P_{5}$ and $P_{20}$ occurs over the entire study area, with the largest increases in the northwest of the region. The MME projects a similar spatial pattern under the two RCPs, but with more increase under RCP8.5.

Compared with the near future, the precipitation changes projected for the end of the twenty-first century show similar directions but with greater magnitudes. In addition, there are increasing differences in the projected changes between the two scenarios for the end of the century, with RCP8.5 showing much greater changes than RCP4.5. By the end of the century, the mean precipitation is expected to increase by $3.7 \%$ under RCP4.5 and 7.3\% under RCP8.5. Precipitation frequency is projected to decrease by $-3.5 \%$ under RCP4.5 and $-6.3 \%$ under RCP8.5. Precipitation intensity is likely to increase moderately $(11.6 \%)$ under RCP4.5, but much more significantly (19\%) under RCP8.5. Extreme precipitation events are projected to increase at a much greater extent. The $P_{5}$ is likely to increase by $42.3 \%$ under RCP 4.5 and $60.4 \%$ under RCP8.5, whereas $P_{20}$ is likely to increase by $47.5 \%$ under RCP4.5 and by $66.7 \%$ under RCP8.5. 


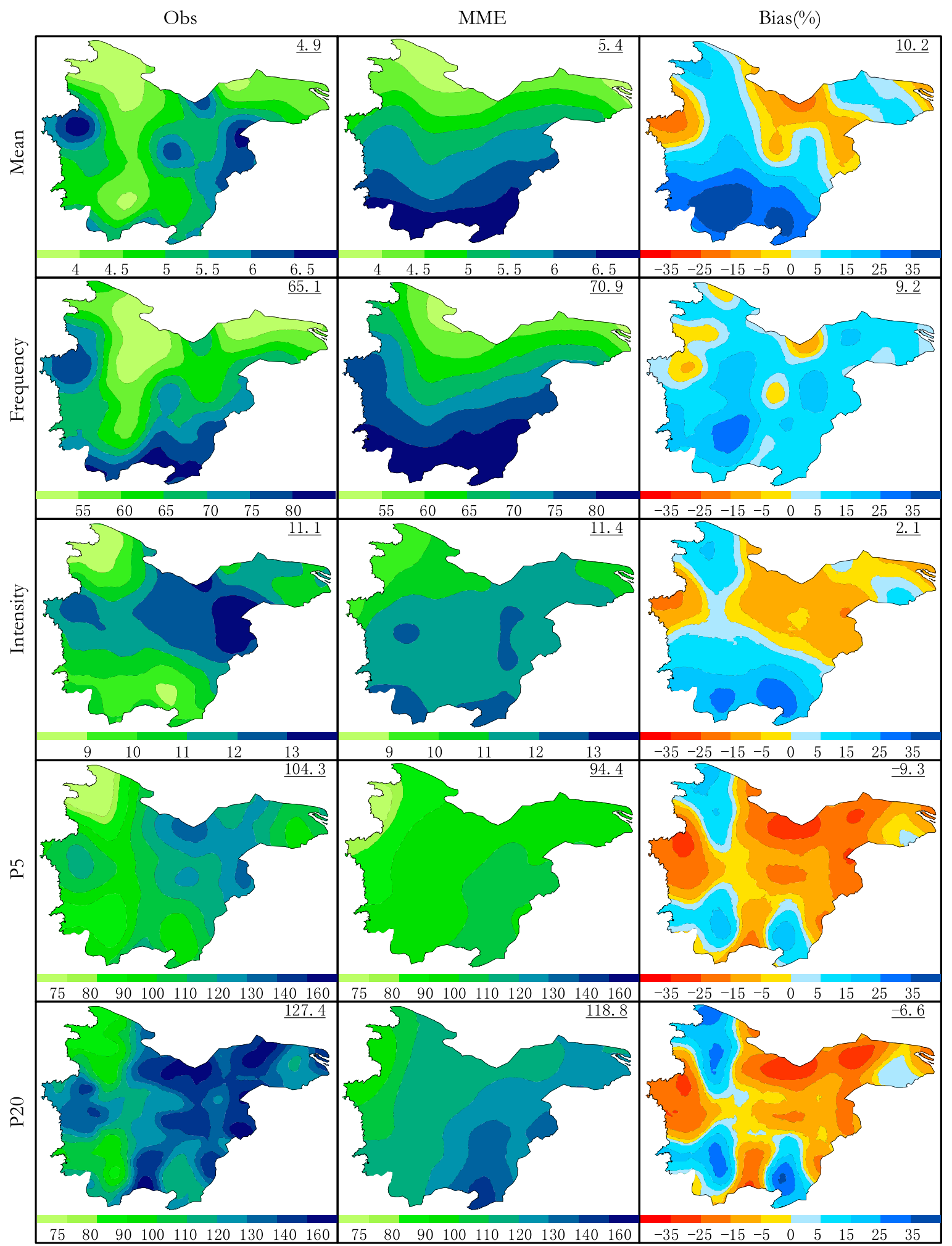

FIG. 3. Spatial distribution of all indices over MLYRB during 1971-2000 from (left) observation, (center) CMIP5 MME, and (right) the differences between the two. 
TABLE 2. Comparison of the min, max, and mean of observed (obs) and the CMIP5 MME and their bias for all indices.

\begin{tabular}{|c|c|c|c|c|c|c|}
\hline \multirow[b]{2}{*}{ Dataset } & \multicolumn{6}{|c|}{ Estimated precipitation } \\
\hline & Min & $\operatorname{Max}$ & Mean & Min bias & Max bias & Mean bias \\
\hline \multicolumn{7}{|l|}{ Mean } \\
\hline Obs & $3.2 \mathrm{~mm}$ & $7.4 \mathrm{~mm}$ & $4.9 \mathrm{~mm}$ & $-36.5 \%$ & $58.0 \%$ & $10.2 \%$ \\
\hline MME & $3.6 \mathrm{~mm}$ & $7.5 \mathrm{~mm}$ & $5.4 \mathrm{~mm}$ & & & \\
\hline \multicolumn{7}{|l|}{ Frequency } \\
\hline Obs & 50.2 day & 95.6 day & 65.1 day & $-22.5 \%$ & $31.8 \%$ & $9.2 \%$ \\
\hline MME & 52.6 day & 89.6 day & 70.9 day & & & \\
\hline \multicolumn{7}{|l|}{ Intensity } \\
\hline Obs & $8.1 \mathrm{~mm} \mathrm{day}^{-1}$ & $14.3 \mathrm{~mm}$ day $^{-1}$ & $11.1 \mathrm{~mm}$ day $^{-1}$ & $-18.5 \%$ & $35.5 \%$ & $2.1 \%$ \\
\hline MME & $9.1 \mathrm{~mm} \mathrm{day}^{-1}$ & $12.5 \mathrm{~mm} \mathrm{day}^{-1}$ & $11.4 \mathrm{~mm}$ day $^{-1}$ & & & \\
\hline \multicolumn{7}{|l|}{$P_{5}$} \\
\hline Obs & $64.5 \mathrm{~mm}$ & $159.4 \mathrm{~mm}$ & $104.3 \mathrm{~mm}$ & $-37.2 \%$ & $28.0 \%$ & $-9.3 \%$ \\
\hline MME & $72.1 \mathrm{~mm}$ & $109.5 \mathrm{~mm}$ & $94.4 \mathrm{~mm}$ & & & \\
\hline \multicolumn{7}{|l|}{$P_{20}$} \\
\hline Obs & $76.3 \mathrm{~mm}$ & $238.2 \mathrm{~mm}$ & $127.4 \mathrm{~mm}$ & $-45.4 \%$ & $45.4 \%$ & $-6.6 \%$ \\
\hline MME & $87.3 \mathrm{~mm}$ & $148.0 \mathrm{~mm}$ & $118.8 \mathrm{~mm}$ & & & \\
\hline
\end{tabular}

The projected changes are consistent with previous studies such as Chen and Sun (2013). In general, relative increases in the extreme precipitation far exceed those in mean precipitation under both RCPs in the twentyfirst century over MLYRB. Such amplified changes in extreme events are also reported by previous studies, such as Sillmann et al. (2013b) for global precipitation change and Feng et al. (2011) for precipitation change in China. In addition, increases in extreme precipitation could also occur in places over MLYRB where mean precipitation is reduced; for example, in the near future the mean precipitation shows a decrease at some parts of MLYRB, while extremes show an increase over the entire MLYRB. Similar results are also found in other places, such as over the subtropics (Emori and Brown 2005), implying that change in mean precipitation is a poor predictor of changes in extreme events. Therefore, it was very important to explore the change in both mean and extreme events, as we did in this study. Our results were largely consistent with previous studies, although the magnitudes of change might differ owing to different methodology applied.

\section{c. The role of the EASM}

Owing to its geographical location, the MLYRB experiences distinct monsoonal climate with a great amount of monsoon precipitation in summer. Changes in the EASM are directly related to the floods and droughts in this region. Many previous studies found a close relationship between the EASM intensity and monsoon precipitation over eastern China, particularly the MLYRB (Li and Zeng 2002; Wu et al. 2016). The current results show that there is negative correlation between monsoon precipitation and the strength of the EASM over the MLYRB (Chan and Zhou 2005; Wang and Yan 2009). This correlation turns positive in northern China. The physical mechanism for this relationship is relatively well understood. Eastern China is dominated by the East Asian monsoon (EAM), caused by the differential solar heating and thermal inertia of land and ocean that establish a land-sea temperature difference. In the summer, this temperature difference triggers the EASM, a low-level flow of moisture from the Pacific Ocean to eastern China. This causes early summer heavy rainfall events along the quasi-stationary mei-yu rain belt, which slowly moves from south to north. The monsoonal rain belt starts in southern China between April and May, moves to the middle part of eastern China (Yangtze and Huai He River basins) in May and July, and moves to northern China in July and August, bringing with it consistent rainfall. Therefore, the rainfall distribution of these regions is closely related to EASM variations. In years when EASM is stronger than usual, the rain belt is pushed farther north, resulting in higher than normal precipitation in northern China and drier conditions in southern China. When EASM is weaker, the rain belt stagnates in southern locations. Northern China then experiences dry conditions, whereas central and southeastern China have higher levels of rainfall. We calculate the annual series of EASM index using monthly mean wind speed at 850-hPa data from both the NCEP-NCAR reanalyses dataset and CMIP5 modeled values for the period from 1971 to 2000, and the results are shown in Fig. 5 and Table 3.

Our results show that the observed EASM intensity exhibits a decreasing trend during the period 1971-2000 (Fig. 5), consistent with previous studies showing the weakening of EASM (Wu et al. 2016). All models except CCSM4 capture this declining trend with varied 


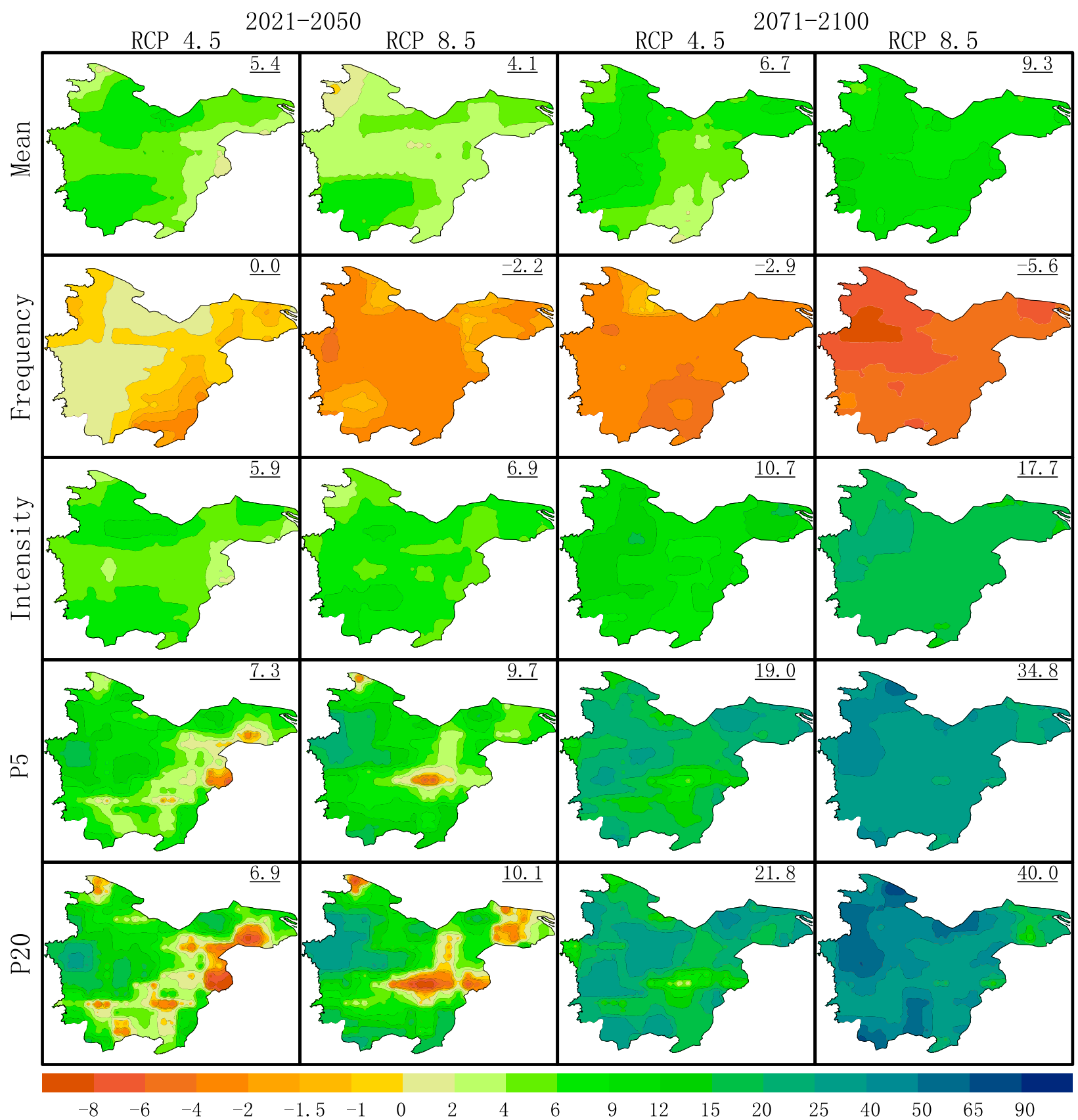

FIG. 4. Percentage change in all indices for the time periods 2021-50 and 2071-2100 relative to the reference period 1971-2000 for RCP4.5 and RCP8.5.

magnitudes, although most models tend to enhance the variability compared with observation. We then perform the correlation analysis between the EASM index and monsoon precipitation for the MLYRB from observed and MME values for 1971-2000. Results are presented in Figs. $6 a$ and $6 b$. They show that monsoon precipitation is negatively correlated with the EASM for most of the MLYRB, but the correlation turns positive toward the southern part of the region. The MME data capture the negative correlation in the northwest, but the correlation starts to turn positive from the midsection of the study region. Overall, the MME does not simulate well the temporal variation of the EASM intensity or the spatial distribution of the correlation between the EASM and monsoon precipitation.

Despite the poor model performance, we still explore the future changes of the EASM, and whether the relationship between the EASM and precipitation over 


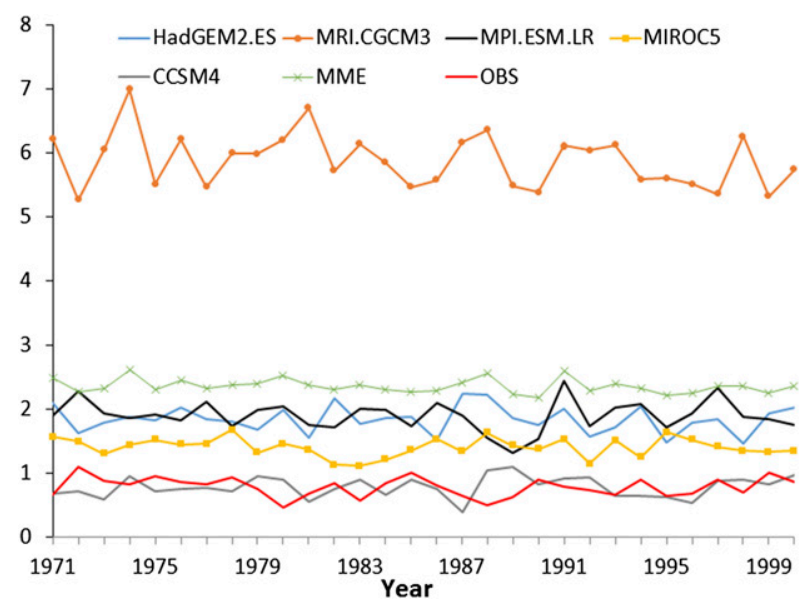

FIG. 5. Time series of the EASM index from 1971 to 2000 from observation, CMIP5 models, and their MME.

MLYRB remains unchanged under global warming. We project the changes in EASM intensity using MME under the RCP4.5 and RCP8.5 emission scenario for 2021-50 and 2071-2100 relative to the 1971-2000 reference period. Results show that the EASM intensity is likely to increase over the twenty-first century. For the near future, it will increase by $2.1 \%$ for RCP 4.5 and $19.7 \%$ for RCP8.5. For the end of the twenty-first century, it will increase by $14.2 \%$ for RCP 4.5 and $14.8 \%$ for RCP8.5. Climate change has the potential to change the EAM circulation pattern. Initial hypotheses suggest that by warming land more than ocean, present climate change could increase the land-ocean temperature difference, enhancing the summer monsoon and weakening the winter monsoon. The monsoon intensity, especially the EASM intensity, are projected to increase in most of the individual CMIP5/CMIP3 models in the twenty-first century under future warming scenarios (Hsu et al. 2012; Hu et al. 2000), which lead to the monsoon precipitation increase over East Asia as a whole (Qing 2012; Chen and Sun 2013; Lee and Wang 2014). The IPCC AR5 report also indicated that, based on CMIP5 model projections, there is medium confidence that, with an intensified East Asian summer monsoon, summer precipitation over East Asia will increase. As our analysis shows, precipitation is also likely to increase over the MLYRB before and after the bias correction.

Monsoon season precipitation is negatively correlated with EASM strength in the observed historical data. If this relationship persists, we should project EASM and precipitation change in different directions. However, both EASM strength and mean precipitation are projected to increase in the twenty-first century under both RCP scenarios. This seems to suggest that the significant
TABLE 3. The mean, trends, and standard deviation (std dev) of the EASM index from observation and CMIP5.

\begin{tabular}{lcccc}
\hline \hline & Mean & Slope $\left[\%(10 \mathrm{yr})^{-1}\right]$ & $p$ value & Std dev \\
\hline Obs & 0.78 & -2.88 & 0.49 & 0.15 \\
CCSM4 & 0.78 & 3.43 & 0.45 & 0.16 \\
HadGEM2-ES & 1.84 & -1.34 & 0.59 & 0.21 \\
MIROC5 & 1.41 & -1.33 & 0.55 & 0.15 \\
MPI-ESM-LR & 1.90 & -1.27 & 0.64 & 0.24 \\
MRI-CGCM3 & 5.89 & -2.42 & 0.11 & 0.43 \\
MME & 2.36 & -1.55 & 0.49 & 0.15 \\
\hline
\end{tabular}

negative correlation between EASM intensity and summer precipitation in the history may no longer exist in the future under the global warming based on the CMIP5 models over MLYRB. However, since the CMIP5 MME does not simulate well the EASM intensity in historical runs, there is great uncertainty as to whether the CMIP5 models can accurately project the EASM intensity change in the future. Moreover, there was no consistent result in previous studies for the future EASM intensity change under the global warming. For example, whereas Lee and Wang (2014) and IPCC AR5 report projected increase in EASM intensity in the future, Jiang and Tian (2013) found no significant change. Furthermore, they indicated that future EASM changes are often model and index dependent, suggesting inadequacy in the models' ability to accurately simulate the EASM. Therefore, the absence of negative correlation between the EASM and precipitation in the twenty-first century projections could either be caused by a change of the existing relationship under the global warming or the inadequacy of CMIP5 models to capture and project this relationship.

\section{Conclusions}

The study first assesses the performance of the CMIP5 models in simulating the mean and extreme precipitation using model output and observed daily values from 1971 to 2000 over the MLYRB. In general the MME outperforms individual models. In terms of spatial patterns, the MME is able to capture the general precipitation gradient over the MLYRB, but not the more complex features associated with orographic precipitation in mountainous regions. The MME shows a positive bias for mean precipitation largely due to overestimation in the rain-shadow regions on the leeward side of mountains. In addition, the MME tends to overestimate the frequency more than intensity over the entire region. In contrast to mean precipitation, the MME underestimated extreme events by $-9.3 \%$ for $P_{5}$ and $-6.6 \%$ for $P_{20}$ for the whole region, but the bias was spatially variable. Based on this assessment, we first 


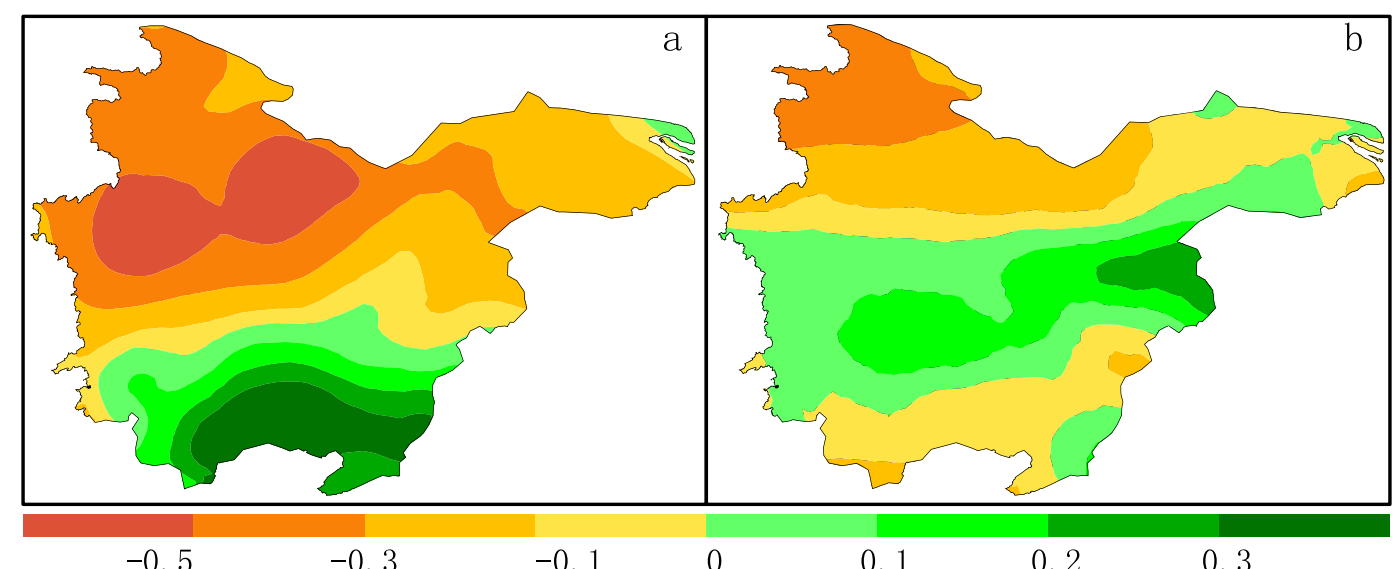

FIG. 6. Correlation coefficient (Pearson's $r$ ) between the seasonal (May-September) EAM index and monsoon mean precipitation from the (a) observation and (b) MME over the MLYRB.

correct the model bias through quantile mapping before the results are used to project future changes.

The bias correction technique can improve the spatial distribution of precipitation projected by the MME, which can potentially increase the accuracy of predictions of changes in precipitation. Thus, the MME after bias correction is used to project future changes in mean and extreme precipitation in the monsoon season over the study area. These changes are projected under two emission scenarios, RCP4.5 and RCP8.5, for the near future (2021-50) and the long-term future (2071$2100)$, relative to $1971-2000$. In the twenty-first century, the models indicate that the monsoon precipitation is likely to get less frequent but more intense under global warming over the MLYRB. Extreme precipitation is projected to increase more than mean precipitation, with even greater relative changes for more extreme events $\left(P_{20}\right)$. The directions of change in mean and extreme precipitation are largely consistent under both emission scenarios, but greater magnitudes of change are projected under the high-emission scenario (RCP8.5). These changes could potentially lead to more devastating floods for this already flood-prone region.

Previous studies suggest a close connection between the weakening of the EASM and the increasing mean and extreme monsoon precipitation over the MLYRB during the past decades based on the observation $(\mathrm{Li}$ and Zeng 2002; Wu et al. 2016). In this study, we further examine the EASM changes and its relation to precipitation change in CMIP5 models. We find that the CMIP5 models do not simulate well the temporal variation of the EASM and the relationship between the EASM and precipitation over MLYRB. Moreover, the negative correlation between the EASM intensity and summer precipitation over the study area is not observed in model output for the twenty-first century under the global warming scenarios. CMIP5 models project increase for both the EASM and summer precipitation.

This inconsistency could be caused by either or both of the following two factors. First, climate models have poor performance simulating spatial distribution of monsoon precipitation and therefore could not capture negative correlation between EASM intensity and precipitation within the study area. Such correlation was not found in the historical runs of climate models. Therefore, the absence of such a relationship in the future could be caused by uncertainties in the performance of climate models. Second, although precipitation in the MLYRB is negatively correlated with EASM intensity, it can be affected by other factors. With intensified monsoon, although the rain belt could be pushed farther northward, other factors, such as general moistening of the atmosphere with higher temperature, could still lead to an increase in precipitation, therefore masking this negative correlation in the future. Further study is needed to evaluate possible changes of the EASM and its connection with the monsoon precipitation in the future with global warming.

Despite some problems with the simulating precipitation over the MLYRB, the CMIP5 models seem to provide relatively robust results of increasing mean and extreme precipitation in the study area. These results could provide critical information for society's longterm planning and adaptation strategies in this economically important flood-prone region in China.

Acknowledgments. This research was partially supported by the National Natural Science Foundation of China (41571180, 41401603, and 41275021) and National Key Basic Research Program of China (2015CB452806). The authors wish to thank the World Climate Research 
Programme's Working Group on Coupled Modelling, who provides the CMIP5 model output, and we thank the China Meteorological Administration for providing the historical climate data for this study. In addition, the Shanghai Normal University and University of Dayton provided facilities for data analysis.

\section{REFERENCES}

Chan, J. C., and W. Zhou, 2005: PDO, ENSO and the early summer monsoon rainfall over south China. Geophys. Res. Lett., 32, L08810, doi:10.1029/2004GL022015.

Chen, H., and J. Sun, 2013: Projected change in East Asian summer monsoon precipitation under RCP scenario. Meteor. Atmos. Phys., 121, 55-77, doi:10.1007/s00703-013-0257-5.

- , and - 2015: Changes in climate extreme events in China associated with warming. Int. J. Climatol., 35, 2735-2751, doi:10.1002/joc. 4168 .

— T. Zhou, R. B. Neale, X. Wu, and G. J. Zhang, 2010: Performance of the new NCAR CAM3.5 in East Asian summer monsoon simulations: Sensitivity to modifications of the convection scheme. J. Climate, 23, 3657-3675, doi:10.1175/ 2010JCLI3022.1.

Chen, L., and O. W. Frauenfeld, 2014: A comprehensive evaluation of precipitation simulations over China based on CMIP5 multimodel ensemble projections. J. Geophys. Res. Atmos., 119, 5767-5786, doi:10.1002/2013JD021190.

Coles, S., 2001: An Introduction to Statistical Modeling of Extreme Values. Springer, 208 pp.

Cooley, D., and S. R. Sain, 2010: Spatial hierarchical modeling of precipitation extremes from a regional climate model. J. Agric. Biol. Environ. Stat., 15, 381-402, doi:10.1007/s13253-010-0023-9.

Emori, S., and S. Brown, 2005: Dynamic and thermodynamic changes in mean and extreme precipitation under changed climate. Geophys. Res. Lett., 32, L17706, doi:10.1029/ 2005GL023272.

Feng, L., T. Zhou, B. Wu, T. Li, and J.-J. Luo, 2011: Projection of future precipitation change over China with a high-resolution global atmospheric model. Adv. Atmos. Sci., 28, 464-476, doi:10.1007/s00376-010-0016-1.

Gudmundsson, L., J. B. Bremnes, J. E. Haugen, and T. EngenSkaugen, 2012: Technical note: Downscaling RCM precipitation to the station scale using statistical transformations-A comparison of methods. Hydrol. Earth Syst. Sci., 16, 3383-3390, doi:10.5194/hess-16-3383-2012.

Hegerl, G., and Coauthors, 2010: Good practice guidance paper on detection and attribution related to anthropogenic climate change. Meeting report of the Intergovernmental Panel on Climate Change Expert Meeting on Detection and Attribution of Anthropogenic Climate Change, T. F. Stocker et al., Eds., IPCC Working Group I Technical Support Unit, University of Bern, 8 pp. [Available online at http://www.ipcc-wg2.gov/meetings/EMs/ IPCC_D\%26A_GoodPracticeGuidancePaper.pdf.]

Hsu, P. C., T. Li, J. J. Luo, H. Murakami, A. Kitoh, and M. Zhao, 2012: Increase of global monsoon area and precipitation under global warming: A robust signal? Geophys. Res. Lett., 39, L06701, doi:10.1029/2012GL051037.

Hu, Z. Z., M. Latif, E. Roeckner, and L. Bengtssn, 2000: Intensified Asian summer monsoon and its variability in a coupled model forced by increasing greenhouse gas concentrations. Geophys. Res. Lett., 27, 2681-2684, doi:10.1029/2000GL011550.
Huang, D. Q., J. Zhu, Y. C. Zhang, and A. N. Huang, 2013: Uncertainties on the simulated summer precipitation over eastern China from the CMIP5 models. J. Geophys. Res. Atmos., 118, 9035-9047, doi:10.1002/jgrd.50695.

Hutchinson, M. F., 1998a: Interpolation of rainfall data with thin plate smoothing splines-Part I: Two dimensional smoothing of data with short range correlation. J. Geogr. Inf. Decis. Anal., 2, 139-151.

_ 1998b: Interpolation of rainfall data with thin plate smoothing splines-Part II: Analysis of topographic dependence. J. Geogr. Inf. Decis. Anal., 2, 152-167.

Jiang, D., and Z. Tian, 2013: East Asian monsoon change for the 21st century: Results of CMIP3 and CMIP5 models. Chin. Sci. Bull., 58, 1427-1435, doi:10.1007/s11434-012-5533-0.

Jiang, T., and Y. Shi, 2003: Global climatic warming, the Yangtze floods and potential loss. Adv. Earth Sci., 18, 277-284.

- Z. W. Kundzewicz, and B. Su, 2008: Changes in monthly precipitation and flood hazard in the Yangtze River basin, China. Int. J. Climatol., 28, 1471-1482, doi:10.1002/joc.1635.

Kharin, V. V., F. Zwiers, X. Zhang, and M. Wehner, 2013: Changes in temperature and precipitation extremes in the CMIP5 ensemble. Climatic Change, 119, 345-357, doi:10.1007/ s10584-013-0705-8.

Knutti, R., and J. Sedláček, 2013: Robustness and uncertainties in the new CMIP5 climate model projections. Nat. Climate Change, 3, 369-373, doi:10.1038/nclimate1716.

—- R. Furrer, C. Tebaldi, J. Cermak, and G. A. Meehl, 2010: Challenges in combining projections from multiple climate models. J. Climate, 23, 2739-2758, doi:10.1175/ 2009JCLI3361.1.

Lee, J. Y., and B. Wang, 2014: Future change of global monsoon in the CMIP5. Climate Dyn., 42, 101-119, doi:10.1007/ s00382-012-1564-0.

Li, J., and Q. Zeng, 2002: A unified monsoon index. Geophys. Res. Lett., 29, 1274, doi:10.1029/2001GL013874.

Pickands, J., III, 1975: Statistical inference using extreme order statistics. Ann. Stat., 119-131.

Pincus, R., C. P. Batstone, R. J. P. Hofmann, K. E. Taylor, and P. J. Glecker, 2008: Evaluating the present-day simulation of clouds, precipitation, and radiation in climate models. J. Geophys. Res., 113, D14209, doi:10.1029/2007JD009334.

Qing, B., 2012: Projected changes in Asian summer monsoon in RCP scenarios of CMIP5. Atmos. Oceanic Sci. Lett., 5, 43-48, doi:10.1080/16742834.2012.11446959.

Shi, L., Y. Ding, and Y. He, 2012: Estimation for geographic and orographic influence on the area rainfall distribution in Yangtze River basin. 2012 IEEE Fifth Int. Conf. on Advanced Computational Intelligence, Nanjing, China, IEEE, 772-775, doi:10.1109/ICACI.2012.6463272.

Sillmann, J., V. Kharin, X. Zhang, F. Zwiers, and D. Bronaugh, 2013a: Climate extremes indices in the CMIP5 multimodel ensemble: Part 1. Model evaluation in the present climate. J. Geophys. Res. Atmos., 118, 1716-1733, doi:10.1002/ jgrd.50203.

— _ _ - F. Zwiers, X. Zhang, and D. Bronaugh, 2013b: Climate extremes indices in the CMIP5 multimodel ensemble: Part 2. Future climate projections. J. Geophys. Res. Atmos., 118, 2473-2493, doi:10.1002/jgrd.50188.

Song, F., and T. Zhou, 2014: Interannual variability of East Asian summer monsoon simulated by CMIP3 and CMIP5 AGCMs: Skill dependence on Indian Ocean-western Pacific anticyclone teleconnection. J. Climate, 27, 1679-1697, doi:10.1175/ JCLI-D-13-00248.1. 
Stephens, G. L., and Coauthors, 2010: Dreary state of precipitation in global models. J. Geophys. Res., 115, D24211, doi:10.1029/ 2010JD014532.

Su, B., T. Jiang, G. Ren, and Z. Chen, 2006: Observed trends of precipitation extreme in the Yangzi River basin during 1960-2004 (in Chinese with English abstract). Adv. Climate Change Res., 2, 9-14.

Taylor, K. E., 2001: Summarizing multiple aspects of model performance in a single diagram. J. Geophys. Res., 106, 71837192, doi:10.1029/2000JD900719.

Tian, D., Y. Guo, and W. Dong, 2015: Future changes and uncertainties in temperature and precipitation over China based on CMIP5 models. Adv. Atmos. Sci., 32, 487-496, doi:10.1007/ s00376-014-4102-7.

Tomassini, L., and D. Jacob, 2009: Spatial analysis of trends in extreme precipitation events in high-resolution climate model results and observations for Germany. J. Geophys. Res., 114, D12113, doi:10.1029/2008JD010652.

Wang, B., Z. Wu, J. Li, J. Liu, C.-P. Chang, Y. Ding, and G. Wu, 2008: How to measure the strength of the East Asian summer monsoon. J. Climate, 21, 4449-4463, doi:10.1175/2008JCLI2183.1.

Wang, S., 2001: Progress in Modern Meteorology (in Chinese). Meteorological Press, $458 \mathrm{pp}$.

Wang, Y., and Z. Yan, 2009: Trends in seasonal precipitation over China during 1961-2007. Atmos. Oceanic Sci. Lett., 2, 165-171, doi:10.1080/16742834.2009.11446798.

Wehner, M. F., R. L. Smith, G. Bala, and P. Duffy, 2010: The effect of horizontal resolution on simulation of very extreme US precipitation events in a global atmosphere model. Climate Dyn., 34, 241-247, doi:10.1007/s00382-009-0656-y.
Wu, J., W. Jiang, C. Fu, B. Su, H. Liu, and J. Tang, 2004: Simulation of the radiative effect of black carbon aerosols and the regional climate responses over China. Adv. Atmos. Sci., 21, 637-649, doi:10.1007/BF02915731.

$\mathrm{Wu}$, S.-Y., 2012: Projecting changes in extreme precipitation in the midwestern United States using North American Regional Climate Change Assessment Program (NARCCAP) regional climate models. Greenhouse Gases: Emission, Measurement and Management, G. Liu, Ed., InTech, 337-354, doi:10.5772/ 32667.

Wu, Y. J., S.-Y. Wu, J. H. Wen, M. Xu, and J. G. Tan, 2016: Changing characteristics of precipitation in China during 1960-2012. Int. J. Climatol., 36, 1387-1402, doi:10.1002/ joc. 4432 .

Wuebbles, D., and Coauthors, 2014: CMIP5 climate model analyses: Climate extremes in the United States. Bull. Amer. Meteor. Soc., 95, 571-583, doi:10.1175/BAMS-D-12-00172.1.

$\mathrm{Xu}, \mathrm{Y}$., and C. Xu, 2012: Preliminary assessment of simulations of climate changes over China by CMIP5 multi-models. Atmos. Oceanic Sci. Lett., 5, 489-494.

— J. Wu, Y. Shi, B. Zhou, R. Li, and J. Wu, 2015: Change in extreme climate events over China based on CMIP5. Atmos. Oceanic Sci. Lett., 8, 102.

Zhai, P., X. Zhang, H. Wan, and X. Pan, 2005: Trends in total precipitation and frequency of daily precipitation extremes over China. J. Climate, 18, 1096-1108, doi:10.1175/JCLI-3318.1.

Zhao, Y. F., 2012: Assessment report for the $0.5^{\circ} \times 0.5^{\circ}$ gridded daily precipitation for China (version 2.0) (in Chinese). National Meteorological Center Rep. 